\title{
Adrenal Insufficiency in Metastatic Lung Cancer
}

\author{
Filipe Carvalho ${ }^{\mathrm{a}}$, Fernanda Louro ${ }^{\mathrm{b}}$, Raed Zakout ${ }^{\mathrm{b}, \mathrm{c}}$
}

\begin{abstract}
We report a case of adrenal insufficiency in patient with lung cancer. Although adrenal metastases are common in cancer patients, adrenal insufficiency is a rare occurrence. Diagnosis and treatment of adrenal insufficiency will improve the physical status and the quality of life in those patients.
\end{abstract}

Keywords: Lung cancer; Metastasis; Adrenal insufficiency

\section{Introduction}

Adrenal glands are a common site for metastases from solid tumors [1]. However, the occurrence of adrenal insufficiency is a very uncommon event [2], as $90 \%$ of the glands must be destroyed to cause adrenal insufficiency [3]. We present a case of a patient with a previously diagnosed non-small cell lung cancer (NSCLC) with known metastatic involvement of the adrenals, which evolved into adrenal failure.

\section{Case Report}

A 60-year-old male patient was admitted to the hospital with several-week history of weakness, adynamia and progressive loss of deambulation, having become bedridden at the last days before the hospitalization.

He was diagnosed 7 months ago with NSCLC in stage IV, with metastasis to the contralateral lung and both adrenal

Manuscript accepted for publication February 25, 2015

aPhysical Medicine and Rehabilitation Department, Hospital Prof. Doutor Fernando Fonseca, E.P.E., Portugal

${ }^{b}$ Department of Medicine I, Hospital Prof. Doutor Fernando Fonseca, E.P.E., Portugal

${ }^{\mathrm{c} C o r r e s p o n d i n g ~ A u t h o r: ~ R a e d ~ Z a k o u t, ~ D e p a r t m e n t ~ o f ~ M e d i c i n e ~ I, ~ H o s p i t a l ~}$ Prof. Doutor Fernando Fonseca, E.P.E., 2720-276 Amadora, Portugal.

Email: rzakout@hotmail.com

doi: http://dx.doi.org/10.14740/wjon890w glands. He also had a history of primary hypertension.

On admission, he was dehydrated and his blood pressure (BP) was $77 / 45 \mathrm{~mm} \mathrm{Hg}$. The rest of the physical examination was irrelevant. Laboratory analyses revealed $\mathrm{Hb} 12.8 \mathrm{~g} / \mathrm{dL}$, sodium $117 \mathrm{mmol} / \mathrm{L}$, potassium $6.2 \mathrm{mmol} / \mathrm{L}$, creatinine 3.09 $\mathrm{mg} / \mathrm{dL}$, blood urea nitrogen (BUN) $123 \mathrm{mg} / \mathrm{dL}$, and C-reactive protein $5.16 \mathrm{mg} / \mathrm{dL}$. Arterial blood gases sample (ambient air) showed $\mathrm{pH}$ 7.437, $\mathrm{PCO}_{2} 19 \mathrm{~mm} \mathrm{Hg}, \mathrm{PO}_{2} 98 \mathrm{~mm} \mathrm{Hg}, \mathrm{HCO}^{3-}$ $12.6 \mathrm{mmol} / \mathrm{L}$, and $\mathrm{SO}^{2-} 98 \%$.

He initiated normal saline infusion and cation exchange resin. Despite sorotherapy he remained hypotensive (BP 70/40 $\mathrm{mm} \mathrm{Hg}$ ), but had mild improvement on laboratory evaluation as follows: sodium $127 \mathrm{mmol} / \mathrm{L}$, potassium $5.3 \mathrm{mmol} / \mathrm{L}$, creatinine $1.85 \mathrm{mg} / \mathrm{dL}$ and BUN $48 \mathrm{mg} / \mathrm{dL}$.

To assess the adrenal function, the next analyses were realized: serum cortisol $3.48 \mu \mathrm{g} / \mathrm{mL}$ (normal 4.3 - 22.4), serum ACTH $181.8 \mathrm{pg} / \mathrm{mL}$ (4.7 - 48.8), serum aldosterone $<1 \mathrm{ng} /$ dL (1 - 16), plasma renin activity $31.76 \mu \mathrm{g} / \mathrm{mL} / \mathrm{h}(0.37-3.84)$ and 24-h urinary cortisol $6.16 \mu \mathrm{g}(28.5$ - 213.7). Computed tomography (CT) scan of the abdomen showed a large nodular enlargement of both adrenal glands.

The diagnosis of metastatic primary adrenal insufficiency was established, and he initiated hormonal replacement therapy with hydrocortisone $5 \mathrm{mg}$ tid and fludrocortisone $0.05 \mathrm{mg}$ qd.

In the following days, the patient presented rapid clinical improvement, with normalization of his blood pressure. Laboratory evaluation also showed normal electrolytes and renal function: $\mathrm{Hb} 9.06 \mathrm{~g} / \mathrm{dL}$, sodium $137 \mathrm{mmol} / \mathrm{L}$, potassium 3.9 $\mathrm{mmol} / \mathrm{L}$, creatinine $1.17 \mathrm{mg} / \mathrm{dL}$, and BUN $21 \mathrm{mg} / \mathrm{dL}$.

On discharge the patient had BP 118/64 mm Hg, and in the subsequent follow-ups he had recovered his autonomous deambulation.

\section{Discussion}

Metastases to the adrenal glands are a frequent finding in patients with advanced malignancies like lung, breast, gastric, and colorectal cancer, melanoma, and non-Hodgkin's lymphoma. This occurs likely due to their rich sinusoidal supply [4]. For instance, large autopsy series have shown that the prevalence of adrenal metastases was as much as $42 \%$ in patients with lung cancer [5].

Most data on patients with adrenal insufficiency due to 
adrenal metastases have been reported as clinical case reports $[3,4,6-27]$. In some of these cases adrenal insufficiency was the presenting feature of occult malignancy $[4,6-8,10,12$, $23-25,27]$. In a prospective study, one-third of patients with bilateral adrenal involvement by metastatic cancer had adrenal insufficiency based on cosyntropin test [28]. Seidenwurm et al found four cases of adrenal insufficiency in 21 patients (19\%) with bilateral adrenal metastases or unilateral adrenal metastases in patients with contralateral adrenalectomy [3]. On the other hand, in one retrospective study of 30 years with 464 patients with adrenal metastatic disease from various tumors, only five of these patients developed adrenal insufficiency [2]. The differences in the frequency of adrenal insufficiency in these studies seem mainly to be due to the pre-selection of the patients and variable diagnostic criteria of adrenal insufficiency, ranging from solely clinical to stimulation tests, with some interpretations of test results questionable due to paraneoplastic endogenous stimulation of the adrenal cortex and the consequent blunt response of cortisol to those tests [29].

Majority of patients with adrenal metastases have activation of the hypothalamic-pituitary-adrenal axis with strongly elevated cortisol levels $[29,30]$. This is explained by the activated hypothalamic-pituitary-adrenal axis due to increased physical and mental stress of tumor patients $[30,31]$ and interaction between the tumor, the immune and the endocrine system [32]. This could explain why adrenal insufficiency is infrequent and develops only in patients with large bilateral metastases [29], with destruction of more than $90 \%$ of the functional cortex [33].

In addition to adrenal insufficiency that develops owing to replacement of both glands by metastases, other causes of adrenal insufficiency in cancer patients include hemorrhagic necrosis of adrenals in the context of metastatic infiltration, impaired adrenal synthesis in patients being treated with some anti-cancer drugs, metastases to the pituitary gland causing secondary adrenal insufficiency [27], and finally, even patients whose adrenal dysfunction is asymptomatic may have inadequate adrenal reserve if they become seriously ill, or can develop relative adrenal insufficiency after withdrawal of steroids included in many treatment protocols. On the other hand, steroids included in many treatment protocols may mask the presence of preexistent adrenal insufficiency.

In patients with cancer, adrenal insufficiency may go unrecognized because the symptoms, such as weakness, anorexia, nausea, vomiting, dehydration and orthostatic hypotension, and laboratory abnormalities, such as hyponatremia, hyperkalemia, and pre-renal azotemia are nonspecific and may be attributed to the underlying progressive malignancy or to the cancer therapy. On the other hand, terminal stage cancer patients can have symptoms that overlap with symptoms of adrenal insufficiency. For instance, in a prospective study of seven patients with adrenal metastases, three of them had symptoms suggestive of adrenal insufficiency that was not confirmed by cosyntropin stimulation test [34].

Patients with bilateral adrenal metastases, particularly those with large bilateral metastases, should be evaluated for the presence of adrenal insufficiency and receive careful follow-up, even if the baseline testing is normal. The treatment of the disease involves life-long administration of glucocorti- coids and mineralocorticoids, which will improve the quality of life.

\section{References}

1. Brunt LM, Moley JF. Adrenal incidentaloma. World J Surg. 2001;25(7):905-913.

2. Lam KY, Lo CY. Metastatic tumours of the adrenal glands: a 30-year experience in a teaching hospital. Clin Endocrinol (Oxf). 2002;56(1):95-101.

3. Seidenwurm DJ, Elmer EB, Kaplan LM, Williams EK, Morris DG, Hoffman AR. Metastases to the adrenal glands and the development of Addison's disease. Cancer. 1984;54(3):552-557.

4. Kung AW, Pun KK, Lam K, Wang C, Leung CY. Addisonian crisis as presenting feature in malignancies. Cancer. 1990;65(1):177-179.

5. Willis RA CW. Pathology of Tumours. British Journal of Surgery. 1948;35(140):446.

6. Zagkotsis GD, Malindretos PM, Markou MP, Koutroumbas GC, Makri PT, Kapsalas DV, Syrganis CD. Adrenal insufficiency as the presenting feature in a patient with lung cancer. J Emerg Med. 2014;46(3):e91-92.

7. Utreras C, Diaz RE, Ascui R, Caro R, Veliz J, Wohllk N. [Addisonian crisis caused by metastatic lung cancer. Report of one case]. Rev Med Chil. 2011;139(9):1196-1200.

8. Faulhaber GA, Borges FK, Ascoli AM, Seligman R, Furlanetto TW. Adrenal Failure due to Adrenal Metastasis of Lung Cancer: A Case Report. Case Rep Oncol Med. 2011;2011:326815.

9. Stern JB, Cosserat J, Strauss C, Girard P, Gossot D, Caliandro R, Magdeleinat P. Abdominal pain and severe hyponatremia after lung cancer surgery. Ann Thorac Surg. 2010;90(1):299-301.

10. Mohammad K, Sadikot RT. Adrenal insufficiency as a presenting manifestation of nonsmall cell lung cancer. South Med J. 2009;102(6):665-667.

11. Yokosuka K, Kawashima T, Okada N, Wakabayashi T, Kawashima S, Kuroda T, Nishi Y, et al. Impaired consciousness caused by a metastatic adrenal tumor of pulmonary adenocarcinoma. Intern Med. 2008;47(2):109112.

12. Sirachainan E, Kalemkerian GP. Unusual presentations of lung cancer: Case 2. Adrenal insufficiency as the initial manifestation of non-small-cell lung cancer. J Clin Oncol. 2002;20(23):4598-4600.

13. Hsu CW, Ho CL, Sheu WH, Harn HJ, Chao TY. Adrenal insufficiency caused by primary aggressive non-Hodgkin's lymphoma of bilateral adrenal glands: report of a case and literature review. Ann Hematol. 1999;78(3):151154.

14. Efremidis SC, Harsoulis F, Douma S, Zafiriadou E, Zamboulis C, Kouri A. Adrenal insufficiency with enlarged adrenals. Abdom Imaging. 1996;21(2):168-171.

15. Dobnig H, Silly H, Ohlinger W, Neubauer M, Leb G, Krejs GJ. Successful treatment of primary adrenal insufficiency due to malignant non-Hodgkin's lymphoma. Clin Investig. 1992;70(10):938-941. 
16. Iqbal MS, Hardman J. Addisonian crisis secondary to bilateral adrenal metastases in rectal carcinoma: report of a rare case and literature review. J Gastrointest Cancer. 2013;44(2):225-227.

17. Bausewein C, Kuhnbach R, Haberland B. Adrenal insufficiency caused by bilateral adrenal metastases -- a rare treatable cause for recurrent nausea and vomiting in metastatic breast cancer. Onkologie. 2006;29(5):203-205.

18. Mor F, Lahav M, Kipper E, Wysenbeek AJ. Addison's disease due to metastases to the adrenal glands. Postgrad Med J. 1985;61(717):637-639.

19. Alpers DH, Engelman K, Foley FD. Addison's disease secondary to carcinoma of the breast. Ann Intern Med. 1962;57:464-467.

20. Butterly JM, Fishman L, Seckler J, Steinberg H. Addison's disease secondary to metastatic carcinoma of the adrenal glands. Ann Intern Med. 1952;37(5):930-939.

21. Galloway JA, Perloff WH. Addison's disease secondary to adrenocortical destruction by metastatic carcinoma of the breast. Am J Med. 1960;28:156-158.

22. Heath H, 3rd, Bergevin PR. Adrenal insufficiency resulting from metastasis of non-functioning adrenocortical carcinoma. Med Ann Dist Columbia. 1973;42(11):545547.

23. Heuson JC. Addison's disease secondary to occult metastatic seminoma. Infarction of the adrenals as the probable mechanism of their destruction. Cancer. 1966;19(11):1754-1759.

24. Rosenthal FD, Davies MK, Burden AC. Malignant disease presenting as Addison's disease. $\mathrm{Br}$ Med J. 1978;1(6127):1591-1592.

25. Sahagian-Edwards A, Holland JF. Metastatic carcinoma to the adrenal glands with cortical hypofunction. Cancer. 1954;7(6):1242-1245.

26. Zimm S, Gardner DF, Walsh JW, Maine CP, Ferguson RH, Smith WK. Addison's disease as the sole clinical manifestation of recurrent bronchogenic carcinoma. South Med J. 1981;74(8):1016-1018.

27. Shah KK, Anderson RJ. Acute secondary adrenal insufficiency as the presenting manifestation of small-cell lung carcinoma. BMJ Case Rep. 2014;2014.

28. Redman BG, Pazdur R, Zingas AP, Loredo R. Prospective evaluation of adrenal insufficiency in patients with adrenal metastasis. Cancer. 1987;60(1):103-107.

29. Lutz A, Stojkovic M, Schmidt M, Arlt W, Allolio B, Reincke M. Adrenocortical function in patients with macrometastases of the adrenal gland. Eur J Endocrinol. 2000;143(1):91-97.

30. Cedermark BJ, Sjoberg HE. Adrenal activity in patients with advanced carcinomas. Surg Gynecol Obstet. 1981;152(4):461-465.

31. van der Pompe G, Antoni MH, Heijnen CJ. Elevated basal cortisol levels and attenuated ACTH and cortisol responses to a behavioral challenge in women with metastatic breast cancer. Psychoneuroendocrinology. 1996;21(4):361-374.

32. Chrousos GP. The hypothalamic-pituitary-adrenal axis and immune-mediated inflammation. $\mathrm{N}$ Engl J Med. 1995;332(20):1351-1362.

33. NW B. The pathologic anatomy in twenty-eight cases of Addison's disease. Arch Pathol. 1929;8:432-450.

34. Cedermark BJ, Sjoberg HE. The clinical significance of metastases to the adrenal glands. Surg Gynecol Obstet. 1981;152(5):607-610. 